\title{
Performance of heterogeneous earthfill dams under earthquakes: optimal location of the impervious core
}

\author{
S. López-Querol ${ }^{1,{ }^{*}}$ and P. J. M. Moreta ${ }^{2}$ \\ ${ }^{1}$ Lecturer, Department of Civil Engineering, University of Castilla La Mancha, Avda. Camilo José Cela s/n, 13071 - Ciudad \\ Real, Spain \\ ${ }^{2}$ MSc Civil Engineering, C/ San Gerardo, 6, 28035, Madrid, Spain \\ *now at: Academic Visitor, Dept. of Civil and Environmental Eng., Imperial College London, UK
}

Received: 17 July 2007 - Revised: 15 November 2007 - Accepted: 3 December 2007 - Published: 10 January 2008

\begin{abstract}
Earthfill dams are man-made geostructures which may be especially damaged by seismic loadings, because the soil skeleton they are made of suffers remarkable modifications in its mechanical properties, as well as changes of pore water pressure and flow of this water inside their pores, when subjected to vibrations. The most extreme situation is the dam failure due to soil liquefaction. Coupled finite element numerical codes are a useful tool to assess the safety of these dams. In this paper the application of a fully coupled numerical model, previously developed and validated by the authors, to a set of theoretical cross sections of earthfill dams with impervious core, is presented. All these dams are same height and have the same volume of impervious material at the core. The influence of the core location inside the dam on its response against seismic loading is numerically explored. The dams are designed as strictly stable under static loads. As a result of this research, a design recommendation on the location of the impervious core is obtained for this type of earth dams, on the basis of the criteria of minor liquefaction risk, minor soil degradation during the earthquake and minor crest settlement.
\end{abstract}

\section{Introduction}

Earth dams are geo-structures usually analysed very carefully from the seismic point of view, because of the risk for the human lives that their failure may imply. During the last century, earth dam engineers have mainly focused their attention on the knowledge of empirical standards of design of these structures against earthquakes, guided by past experiences (Sherard, 1967). The characteristics of the materials to be used in each zone of the dam have been widely investigated as well. A significant event in the design of earthfill dams was the failure of the lower San Fernando dam (Los

Correspondence to: S. López-Querol

(mariasusana.lopez@uclm.es)
Angeles area), in the earthquake of the same name, which took place in 1971. Some laboratory and field researches after this event demonstrated that the flow failure of the liquefied upstream sand fill happened few minutes after the end of the earthquake (Fig. 1) (Seed et al., 1973, 1989; Bardet and Davis, 1996; Zienkiewicz et al., 1999; Wu, 2001; Ming and Li, 2003; Blázquez and López-Querol, 2007). Due of the great amount of reported data about this dam, it has become the main case study used for validating a lot of constitutive laws for saturated soils under vibrations developed after that year. Nevertheless, although it is the most famous case of liquefaction failure of an earth dam, it is not the only one taken place in the past (Seed, 1979; Wylie et al., 1975; Davis and Bardet, 1996; Olson, 2001; Olson and Stark, 2002).

Since 1971, a lot of analyses of possible liquefaction in already constructed earth dams located at seismic sites have been made, in order to upgrade the most dangerous ones against human casualties (Mejia et al., 2005). There is not too much research about the design of new earth dams at those sites, especially in what concerns to geometry and location of the impervious core. Nevertheless, it is sanctioned by the practice that, if the seismic risk is high, the location of the impervious core close to the upstream slope is better than a central core (Finn and Khanna, 1966; Vallarino, 2001), and this kind of cross sections is frequently used at sites where the seismic risk ranges from medium to high (Wieland and Malla, 2002). But this issue is again more an experience knowledge than a scientifically analysed phenomenon.

Usually, the constitutive laws for modelling the soil behaviour under static loads are not applicable to vibrations. Several constitutive laws are specifically suitable for dynamic loadings (Martin et al., 1975; Dafalias and Popov, 1976; Blázquez et al., 1980; Prevost, 1985; Pastor et al., 1990; Bardet, 1995; Manzari and Dafalias, 1997; Gajo and Wood, 1999; Papadimitriou et al., 2001). Some approaches have been carried out in order to model the dynamic sand behaviour by means of densification based models, in which the

Published by Copernicus Publications on behalf of the European Geosciences Union. 

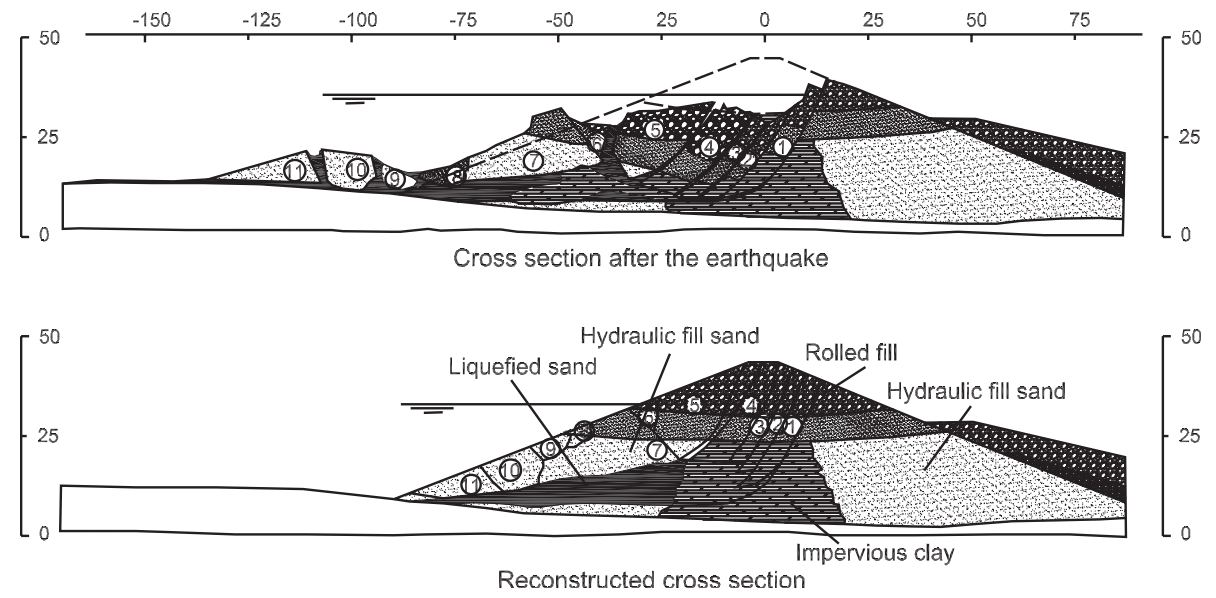

Fig. 1. Geometry of the lower San Fernando Dam after and before the failure in 1971. Distances given in meters (after Seed et al., 1989).

rate of pore water pressure increase is related to the changes of volumetric strain of the sand when it is dry or totally drained. This type of modelling realistically represents the physical process of the loss of effective stress for loose sand, in which the behaviour is mainly contractive, but the dilative trend of dense sand can not be taken into account in some of them. In this paper, a model based on a densification law, with a flow rule for predicting the dilative behaviour and soil collapse, has been used. In addition, the microstructural changes of the soil after phase transformation and collapse are modelled as well (Ishihara et al., 1975; Alarcón-Guzmán et al., 1988).

This constitutive model has been implemented in a coupled 2-D finite element code newly developed by the authors, which has been deterministically applied to several ideal cross sections of earth dams with impervious core. All of these dams have been designed as $100 \mathrm{~m}$ height, and have the same volume of impervious material in the core, but the main difference between them is the location of this core inside of the dam, which ranges from totally centered to totally leaned to the upstream slope. Both upstream and downstream slope angles have been previously calculated in order to make the dams strictly stable under static loadings. Two different earthquakes have been applied at the base of all these dams, in order to explore their risk against failure due to liquefaction and crest settlements. On the basis of this analysis, a design recommendation of the impervious core location for the studied case at seismic sites is numerically obtained.

In this paper the governing equations used in the numerical model are firstly provided. After that, the applied constitutive law is briefly described. The applied dynamic loadings, geometry, material characteristics and boundary conditions of the analysed dams are presented, and the numerical results are evaluated, in order to determine the optimal location of the impervious core inside the dam against liquefaction between all the analysed cases.

\section{Governing equations}

The mechanical behaviours of both solid and fluid phases subjected to dynamic loading, as well as the coupling between them, are given by Biot's equations, in which the transmission of waves in saturated porous media is accounted for (Biot, 1956; Zienkiewicz et al., 1999). The $u-w$ formulation is employed herein ( $u$ and $w$ denote, respectively, the absolute displacement of the solid phase and the relative displacement of the fluid phase). If linear approximation functions are used in the finite element scheme, compared to the more conventional $u-p_{w}$ formulation ( $p_{w}$ denotes the pore water pressure), the $u-w$ formulation gives stable solutions even for extremely low values of the soil permeability (López-Querol and Blázquez, 2006), and no stabilization algorithms are needed (Mira et al., 2003). In addition, while in $u-p_{w}$ formulation the relative flow acceleration is neglected, in $u-w$ it is not, and therefore, more accurate solutions are obtained if the frequency of the input motion and/or the soil permeability are high (Zienkiewicz et al., 1980). The incremental governing equations, in each time step, are finally rearranged as follows, using matrix notation:

$$
\begin{aligned}
& \left(\mathbf{S}^{T} \mathbf{D}^{e} \mathbf{S}-\mathbf{S}^{T} \mathbf{D}^{e} \mathbf{D}^{p} \mathbf{S}\right) d u+M_{d} \nabla\left(\nabla^{T} d u\right)+ \\
& +M_{d} \nabla\left(\nabla^{T} d w\right)-\rho d \ddot{u}-\rho_{f} d \ddot{w}+\rho d b=0 \\
& M_{d} \nabla\left(\nabla^{T} d u\right)+M_{d} \nabla\left(\nabla^{T} d w\right)-\mathbf{k}^{-1} d \dot{w}- \\
& -\rho_{f} d \ddot{u}-\frac{\rho_{f}}{n} d \ddot{w}+\rho_{f} \boldsymbol{d} b=0
\end{aligned}
$$

Equation (1) stands for the equilibrium of the saturated two-phase medium (solid and fluid phases of the soil), and Eq. (2), only for the fluid phase. In these equations, $M_{d}$ is the tangent constrained modulus of the drained sand in unloading; $\rho$ and $\rho_{f}$ are the densities of the two-phase medium and the fluid, respectively; $n$ is the porosity of the soil; $\mathbf{k}$ is the soil permeability tensor (expressed in units of [lenght $]^{3} \cdot[$ time $] /[$ mass $]$ ), $\boldsymbol{d} \boldsymbol{b}$ is the 

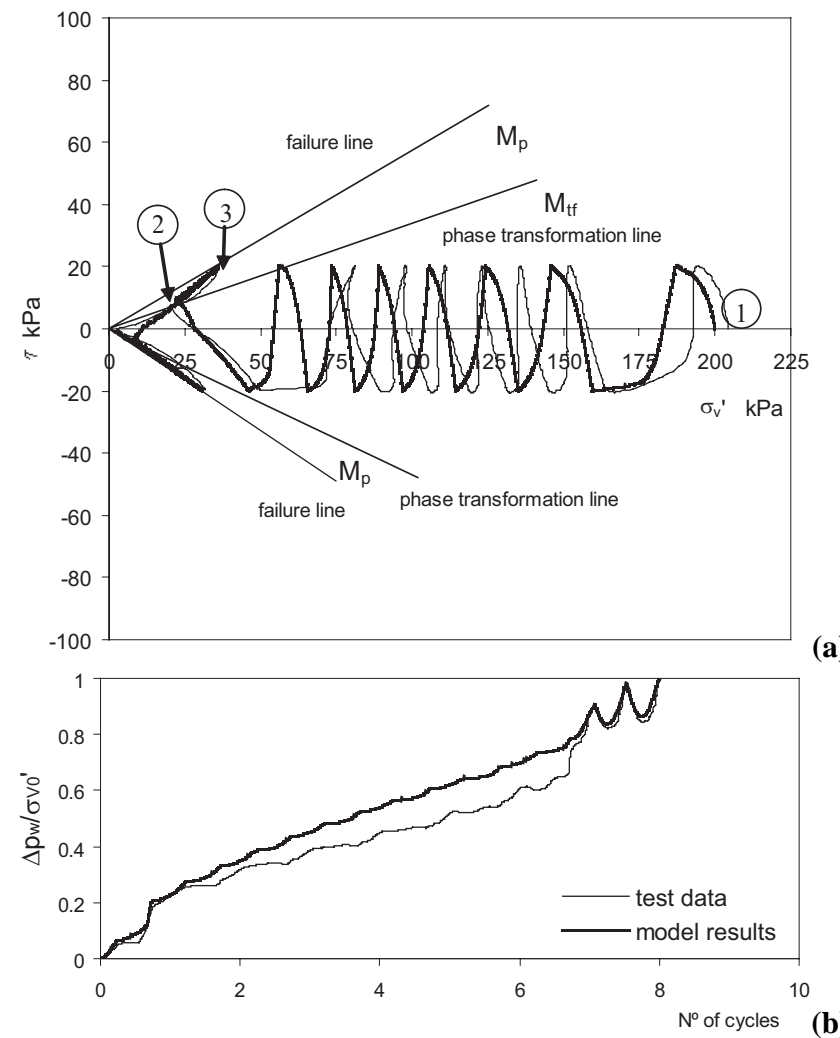

(b)

Fig. 2. Cyclic shear stress test on loose saturated undrained sand: experimental data vs. constitutive model numerical results. (a) Stress path, failure and phase transformation lines. (b) Liquefaction degree $\left(\Delta p_{w} / \sigma_{v 0}^{\prime}\right)$ (after Wijewickreme et al., 2005).

vector of incremental external acceleration due to the earthquake; $\mathbf{S}$ is an operator which in 2-D is given by:

$S=\left(\begin{array}{cc}\partial / \partial x & 0 \\ 0 & \partial / \partial y \\ \partial / \partial y & \partial / \partial x\end{array}\right)$

$\mathbf{D}^{\mathbf{p}}$ is the tensor which defines the constitutive law of the material; $\mathbf{D}^{\mathbf{e}}$ is the elastic tensor, which, in plane strain, and for the constitutive law used herein, is defined as follows:

$\mathbf{D}^{\mathbf{e}}=\frac{\lambda}{v}\left(\begin{array}{ccc}1-v & v & 0 \\ v & 1-v & 0 \\ 0 & 0 & \frac{1-2 v}{2} \frac{G^{*}}{G}\end{array}\right)$

$v$ is the Poisson's coefficient, $G^{*}$ is a function defined by means of the constitutive law, and $\lambda$ is the Lamé constant:

$\lambda=\frac{2 G v}{1-2 v}$

and $G$ is given by:

$G=\frac{G_{\max }}{T}$

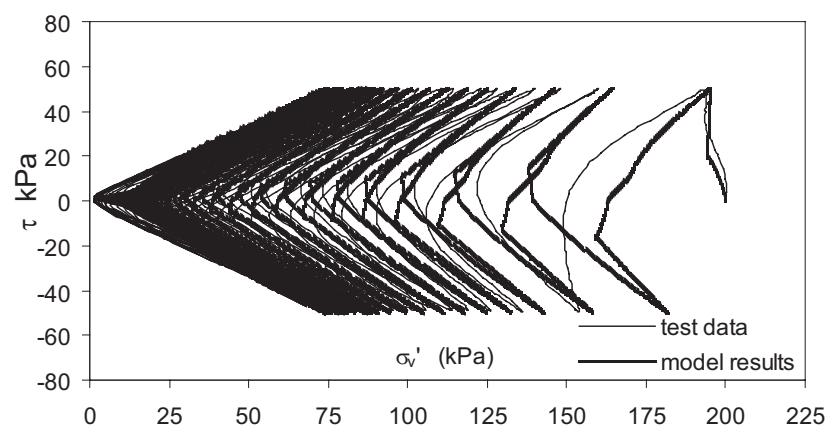

Fig. 3. Cyclic shear stress test on dense saturated undrained sand. Stress path: experimental data vs. constitutive model numerical results (after Wijewickreme et al., 2005).

where $G_{\max }$ is the maximum tangent shear elastic modulus, depending on the void ratio, $e$, and the effective overburden pressure, $p^{\prime}$, and can be computed as:

$G_{\max }=\frac{B_{g} \cdot p_{a}}{0.3+0.7 \cdot e^{2}} \cdot\left(\frac{p^{\prime}}{p_{a}}\right)^{2}$

$B_{g}$ is a sand dependent model parameter, $p_{a}$ is the atmospheric pressure (in the same units as $p^{\prime}$ ), and $T$ is a function which quantifies the degree of non-linearity of the soil behavior, in the following manner:

- First loading:

$$
T=1+2 \cdot C_{t} \cdot\left|\eta-\eta_{0}\right|
$$

- Unloading and reloading:

$$
T=1+C_{t} \cdot\left|\eta-\eta_{s r}\right|
$$

In Eqs. (8) and (9), $C_{t}$ is a material constant, and $\eta, \eta_{0}$ and $\eta_{s r}$ represent, respectively, the current, initial and last reversal values of the stress ratio, $\tau / \sigma_{v}^{\prime}$.

In Eq. (2), the term $\mathbf{k}^{-1} d \dot{w}$ stands for the viscous coupling between solid and fluid phases, on the basis of the assumption of the porous media flow Darcy's law.

\section{Constitutive law for dynamic loadings}

The constitutive law applied in the numerical model (Eq. 1) was derived by López-Querol and Blázquez (2006). It is based on the calculation of the plastic volumetric strains of dry sandy soil under vibrations (densification), which are related to the changes in the effective stress of the saturated soil. This law is briefly described herein.

Figure 2 shows a typical result obtained from a saturated undrained sand subjected to cyclic shear stress test (Wijewickreme et al., 2005). In Fig. 2a the stress path is shown. The initial effective stress, $\sigma_{v 0}^{\prime}$, is depicted as point 1 . Cycle 


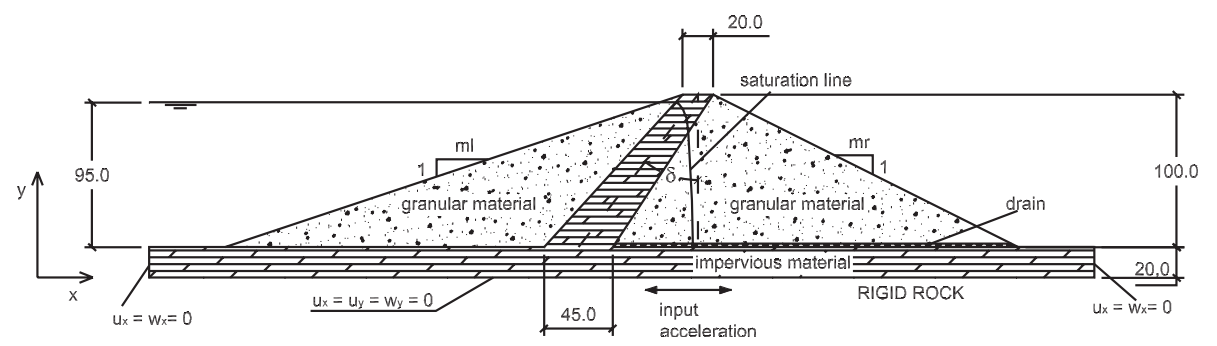

Fig. 4. Geometry of the studied earth dams. Saturation line, types of material and boundary conditions.

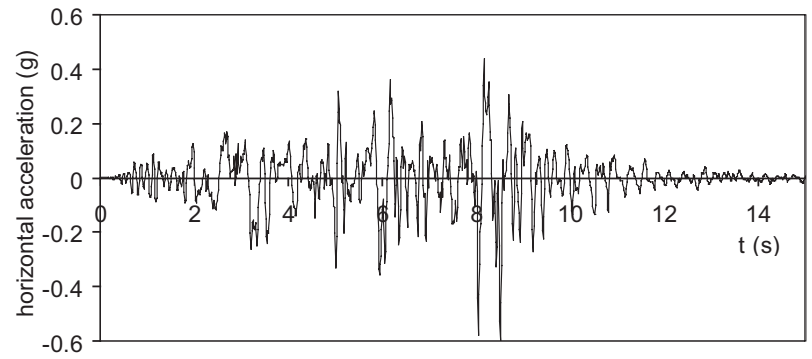

(a)

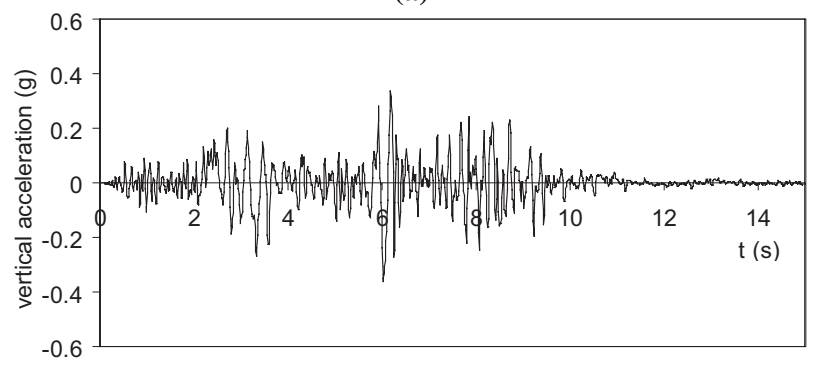

(b)

Fig. 5. Recording at the Pacoima dam (CDMG Station 279), San Fernando earthquake (9 February 1971), scaled to a maximum horizontal acceleration, $\left|a_{\mathrm{hmax}}\right|=0.6 \mathrm{~g}$. (a) Horizonal accelerogram (254). (b) Vertical accelerogram. (http://nisee.berkeley.edu/).

by cycle, the effective stress, $\sigma_{v}^{\prime}$, decreases until the stress path reaches the phase transformation line (point 2): until this point, the sand behaves in contractive manner. From this point until unloading (point 3 ), the sand dilates, recovering some of the effective stress. Figure $2 \mathrm{~b}$ shows the evolution of the liquefaction degree $\left(\Delta p_{w} / \sigma_{v 0}^{\prime}\right.$, where $\Delta p_{w}$ is the excess pore water pressure generated during the earthquake) in the same test. It is worth to point out that, as the liquefaction degree approaches to $1, \Delta p_{w}$ is more similar to $\sigma_{v 0}^{\prime}$, which means that the current effective stress, $\sigma_{v}^{\prime}$, approaches to zero, if Terzaghi's stress decomposition law is assumed: $\sigma_{v}^{\prime}=\sigma_{v 0}^{\prime}-\Delta p_{w}$. At the beginning of the loading, the water pressure gradually increases, and during the last cycles of loading, it decreases and increases in each cycle, because at these stages, dilation and contraction take place in an alternative manner.
In Fig. 2a, the failure lines in both positive and negative shear stress planes (with slope $M_{p}$ ) are sketched. These lines are never crossed by the stress path. The looser the sand, the closer the failure and phase transformation lines (the sand behaviour is mainly contractive). In dense sand, the slope of the phase transformation lines, $M_{t f}$, is quite different from the slope of the failure lines, and the sand behaviour is mainly dilative since the beginning of the loading. An example of a stress path in a saturated dense sand under cyclic shear stress conditions is given in Fig. 3. This mainly dilative behaviour is known as cyclic mobility.

For the constitutive law used in this research, for both contractive and dilative behaviours, the constitutive law tensor, $\mathbf{D}^{\mathbf{p}}$, can be written as follows:

$\mathbf{D}^{\mathbf{p}}=\left(\begin{array}{ccc}0 & 0 & 0 \\ 0 & 0 & Q_{q} \\ 0 & 0 & K_{q}\end{array}\right)$

$K_{q}$ is determined by applying the following equation:

$K_{q}=\frac{\tau \cdot \operatorname{sign}(d \gamma)}{G \cdot \tau_{D}\left(1+\frac{\alpha^{\prime}}{\beta} \xi\right)}$

where $\tau$ is the current shear stress, $d \gamma$ is the increment of shear strain, both in the current time step; $\tau_{D}, \alpha^{\prime}$ and $\beta$ are model constants; and $\xi$ is a function determined incrementally:

$d \xi=|d \gamma|$

If, at the beginning of the current time step, the stress path is in the contractive zone:

$G^{*}=G$

and $Q_{q}$ is obtained from the following equation:

$Q_{q}=-I_{s}\left(\frac{n}{4}\right) \frac{|100 \gamma|^{n-1} \operatorname{sign}(d \gamma)}{1+\alpha \cdot \zeta}$

where $n, \alpha$ are generalized for different quartzitic sands and non harmonic loadings, and computed as follows, in each time step (Blázquez and López-Querol, 2006):

$n=C \cdot N^{-D}$ 
Table 1. Values of the upstream (ml) and downstream (mr) slopes for equilibrium under static loads, as a function of the angle of the impervious core, $\delta$ (horizontal distance per one unit of vertical distance).

\begin{tabular}{lll}
\hline$\delta($ degree $)$ & $\mathrm{ml}$ & $\mathrm{mr}$ \\
\hline 0.0 & 3.5 & 1.8 \\
20.0 & 3.6 & 1.7 \\
40.0 & 3.9 & 1.6 \\
60.0 & 4.2 & 1.6 \\
76.2 & 4.2 & 1.5 \\
\hline
\end{tabular}

$\alpha=A \cdot \ln (N)+B$

$N$ is the number of cycles of harmonic strain amplitude, and:

$A=\frac{1}{2} \cdot\left(\frac{e_{\max }^{2}-e_{\min }^{2}}{1+e_{\max }-D r_{0} \cdot\left(e_{\max }-e_{\min }\right)}\right)$

$B=\frac{1}{2} \cdot\left(e_{\max }^{2}-e_{\min }^{2}\right)+1$

$D=\frac{1}{2} \cdot\left(e_{\max }^{2}-e_{\min }^{2}\right)$

where $e_{\max }$ and $e_{\min }$ are the maximum and minimum void ratios. Proceeding in this way, the total number of parameters to be calibrated for the densification law becomes only one, namely $C$, which varies linearly with the initial relative density, $D r_{0}$, for some analysed sands.

$I_{S}$ depends on the type of sand, initial relative density and degradation suffered since the beginning of the vibrations. It is equal to 1 before phase transformation and/or collapse, and bigger than one after some of those situations have taken place. $\zeta$ is incrementally determined as follows:

$d \zeta=\frac{n}{4}|100 \gamma|^{(n-1)}|d \gamma|$

On the other hand, if sand behaves in dilative manner, $G^{*}$ and $Q_{q}$ must be calculated as:

$G^{*}=\frac{\operatorname{sign}(\tau) \psi M_{p} M_{d} Q_{q}}{1-K_{q}}$

$Q_{q}=\operatorname{sign}(\tau) \psi\left(1+\alpha_{p}\right) K_{q}$

where $\alpha_{p}$ is a soil parameter, $\psi$ is a degradation parameter:

$\psi=\frac{G_{0}}{G_{0}-G}$

and $G_{0}$ is the initial tangent elastic modulus.

Finally, for quartzitic sands, $M_{d}$ can be obtained from the next equation:

$M_{d}=\frac{K_{d} \cdot \sigma_{v}^{\prime 0.5}}{\sigma_{v 0}^{\prime m *}}$
Table 2. Parameters used for the materials in the numerical model (López-Querol and Blázquez, 2006), and for the slope stability analysis under static loadings.

\begin{tabular}{lcr}
\hline Parameter & Sand & Impervious soil \\
\hline$C$ & 10 & 0 \\
$K_{d}$ & 12000 & 1 \\
$m^{*}$ & 0.372 & 0.372 \\
$\alpha_{p}$ & -0.99 & -0.99 \\
$I_{s}$ (before phase tr. and/or collapse) & 1 & 1 \\
$I_{S}$ (after phase tr. and/or collapse) & 2 & 2 \\
$B_{g}$ & 220 & 170 \\
$C_{t}$ & 1.6 & 1.0 \\
$e_{\min }$ & 0.68 & 0.50 \\
$e_{\max }$ & 1.00 & 1.00 \\
$D r_{0}$ & 0.60 & 0.64 \\
$M_{p}$ & 0.65 & 1.20 \\
$M_{t f}$ & 0.17 & 0.28 \\
$k(\mathrm{~m} / \mathrm{s})$ & $4.3 \times 10^{-4}$ & $0.5 \times 10^{-8}$ \\
$\gamma_{s}\left(K N / \mathrm{m}^{3}\right)$ & 26.56 & 26.17 \\
$c^{\prime}\left(K N / \mathrm{m}^{2}\right)$ & 5 & 30 \\
$\varphi^{\prime}($ degree $)$ & 35 & 20 \\
\hline
\end{tabular}

where $K_{d}$ and $m *$ are sand dependent parameters, and $\sigma_{v 0}^{\prime}$ and $\sigma_{v}^{\prime}$ denote initial and current effective stress, respectively. It has been assessed that this constitutive law is suitable for reproducing both free field and laboratory (centrifuge tests) soil profiles under dynamic loadings (LópezQuerol and Blázquez, 2007; Blázquez and López-Querol, 2007). Figures 2 and 3 also show numerical results compared to experimental measurements after calibration. This constitutive model has been proved to be accurate enough for determining the pore water pressure changes, and the computed strains and displacements are in reasonable good agreement with the observations.

\section{Application of the model}

\subsection{Geometry and materials of the analysed dams}

Figure 4 shows a sketch of the analysed earth dam cross sections. All of them are $100 \mathrm{~m}$ height. The angle between the axis of the impervious core and the $y$ axis (vertical), $\delta$, has been made variable from zero to the angle of the upstream slope (core totally leaned to this slope). The volume of the impervious core is the same in all the dams. Five earth dam cross sections have been analysed. Both upstream and downstream slopes have been determined in order to make the dams strictly stable under static loadings (without earthquake), by applying the Bishop's method, and considering the materials of the dam as isotropic and Mohr-Coulomb type. The calculation of the downstream slope has been made on the basis of the assumption that the maximum water elevation is five meters under the crest of the dam. For determining the upstream slope, the fast drainage of the reservoir has been 

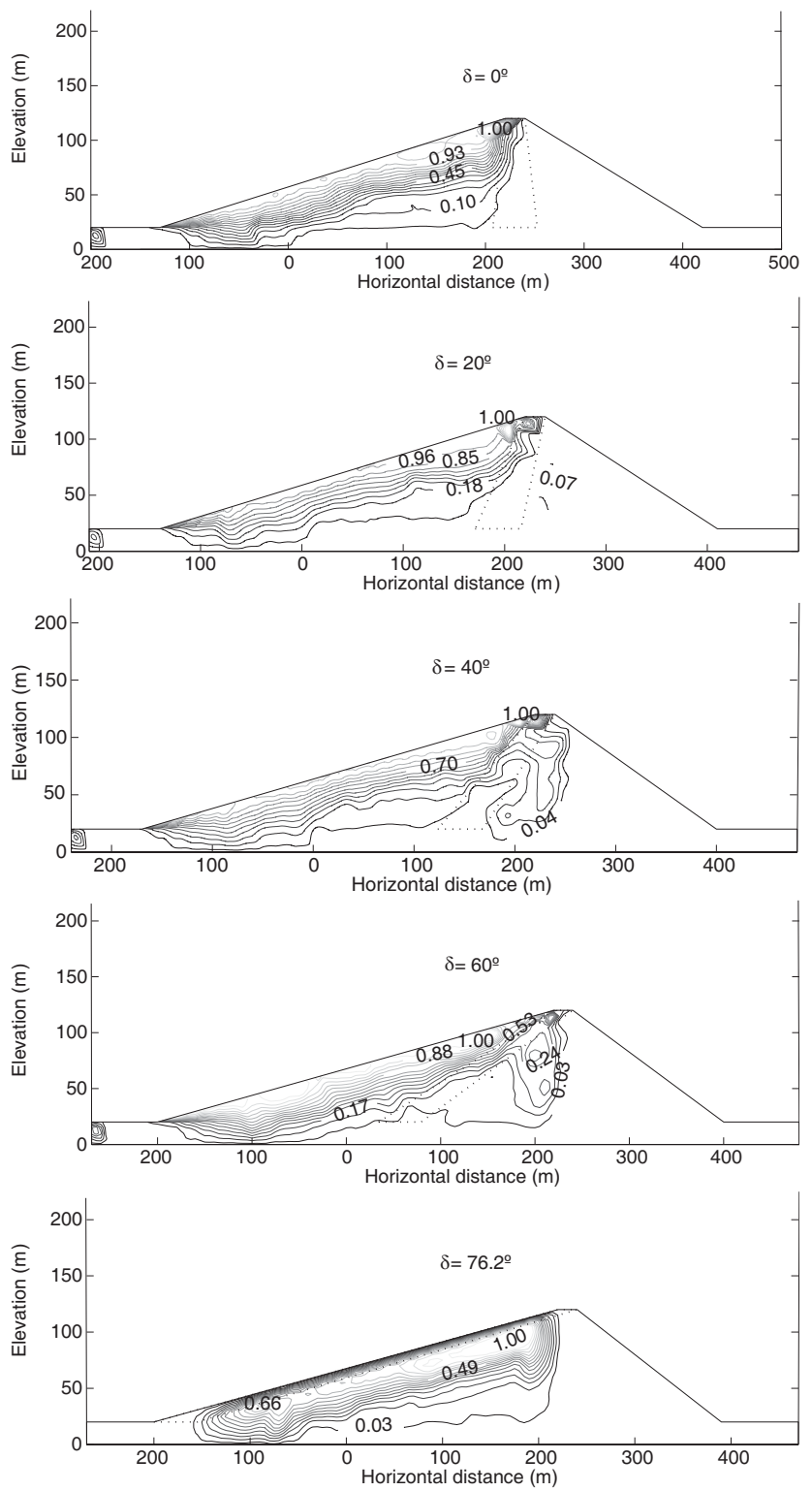

Fig. 6. Computed liquefaction degree $r_{u}=\Delta p_{w} / \sigma_{v 0}^{\prime}$ in the analysed dams at the end of the San Fernando earthquake (subjected only to its horizontal component).

assumed, and the water table has been considered remaining at the top of the slope surface. The results of these slopes are provided in Table 1 (horizontal distance per one unit of vertical distance). The parameters of the soils for the static stability analysis (cohesion, $c^{\prime}$, internal friction angle, $\varphi^{\prime}$, and specific weight of the solid skeleton, $\gamma_{s}$, which, knowing the inicial void ratio and saturation conditions, allows us to calculate the apparent density) as well as the values of the parameters in the constitutive model described in Sect. 3, can be checked in Table 2. The used values are typical for both granular and impervious soils, respectively.
Although the described constitutive model is strictly valid only for granular soil, it can be also employed for more impervious soils in a simplified manner, by taking an extremely low value of the parameter $K_{d}$. By so doing, the rate of evolution of excess pore water pressure is very low in these soils, circumstance that correctly fits the experimental results (López Querol, 2005). The permeability of this material is a typical value for this type of soil.

\subsection{Numerical results}

The numerical model described in Sect. 2 has been applied to the five earth dam cross sections with different angle $\delta$. Since most of the soil volume in the dam consists of sandy material, above the saturation line the soil is assumed to be completely dry, and below it, totally saturated. The dams are supposed to rest over a $20 \mathrm{~m}$ thick soil layer, which is over rigid rock. The horizontal accelerogram recorded at the Pacoima dam in the San Fernando earthquake in 1971 (Los Angeles area, 254, CDMG Station 279), scaled to the maximum horizontal acceleration of $0.6 \mathrm{~g}$, is the one firstly applied to the base rock of all the dams (Fig. 5a). This accelerogram is very similar to the ones usually employed in the studies of the failure of the lower San Fernando dam (Seed, 1979). After using only this horizontal input motion, a new computation has been carried out, in which the vertical accelerogram of the same earthquake, recorded at the same station, and scaled by the same factor than the horizontal component, has been also applied (Fig. 5b). Since the constitutive model used herein is based on the excess pore water pressure evolution due to the accumulation of shear strains in the soil, mainly caused by shear stresses, the vertical acceleration is expected to modify the dam response in terms of vertical coupling of fluid and solid phases, modifiying the consolidation conditions.

Figure 6 displays the liquefaction degrees $\left(r_{u}=\Delta p_{w} / \sigma_{v 0}^{\prime}\right)$ at the end of the San Fernando earthquake, only applying its horizontal accelerogram to the five studied dams. The geometry of the dams and the core inside them are also sketched. It is worth to point out that values of $r_{u}$ equal to 1 mean that liquefaction has occurred. Therefore, on the basis of this figure, the five dams reach liquefaction at the end of the earthquake. The critical points (where the maximum values of $r_{u}$ are reached) in the first three dams are located at the higher elevation of the boundary between impervious and granular materials. In the fourth dam ( $\delta=60$ degree), the most critical point against liquefaction is located slightly at a lower elevation, but also close to the surface of the upstream slope of the dam. The fifth dam, in which the core is located at the upstream slope, liquefaction takes place in a less concentrated zone of the dam, at the top of the contact between earthfill and impervious material.

In Fig. 7, the deformed shapes of the dams (amplified by 50) at $t=8.52 \mathrm{~s}$ (which is the time when the maximum acceleration is applied at the base rock, Fig. 5a) can be seen. The arrows represent the velocity of the water flow inside 
the dams. In these graphics, the location of the impervious core in each dam is again depicted. At the most superficial locations the vectors show the exit of the water towards the reservoir, because consolidation is taking place. However, in the last dam the core works as an impervious barrier against the water flow to the reservoir, and water only moves inside the dam. In this case, the consolidation is a slower process which takes place after the end of the earthquake, and the water does not flow to the reservoir unless the core is broken. Therefore, if the resistance of the core is assessed, this consolidation process gives more stability to this dam if compared to the others, because it is well known that in the above mentioned lower San Fernando dam, the upstream slope failed few minutes after the earthquake, during the consolidation stages, because of the instability produced by the porous media flow of the water towards the reservoir (Seed et al., 1973; Zienkiewicz and Xie, 1991; Blázquez and López-Querol, 2007). In Fig. 8 the degradation of the materials of the dam at the end of the San Fernando earthquake against the angle of the impervious core, $\delta$, is pointed out. Results for only horizontal accelerations and both horizontal and vertical input motions applied together are provided. The percentages of the volume of the dam material over the liquefaction degrees $r_{u}=0.2,0.6$ and 0.9 are depicted for both loading cases. The most important results are those related to $r_{u} \geq 0.9$, because if the soil reaches this value, it is very close to the onset of liquefaction. Curves for $r_{u} \geq 0.2$ and $r_{u} \geq 0.6$ are drawn as well, in order to point out the degradation state of the material in each whole dam.

Figure 9 represents the vertical displacement computed at the crest of the dams at the end of the San Fernando earthquake, also for both loading situations (only horizontal and both horizontal and vertical recordings). The negative sign means settlement.

Just for not to base the conclusions of this research in a single input motion, one more accelerogram has been used. In this case, the loading is a recording reported by Byrne (2005), which has a $2 \%$ probability of being exceded in 50 years in the Vancouver area (Fig. 10). In the previous case of the San Fernando earthquake, if only horizontal or both horizontal and vertical accelerations are taken into account, the selection of the optimal cross section is the same, as it will be justified within the next section (although some differences arise in the computation of liquefaction degrees and crest settlements). Therefore, in this second case, only the horizontal component of the earthquake is considered. Percentages of the material in the dams over three liquefaction degrees (again, 0.2, 0.6 and 0.9), and crest settlements, are respectively given in Figs. 11 and 12 for this new input motion.

\section{Optimal cross section}

In order to obtain the optimal cross section of earth dams with impervious core against liquefaction at seismic sites
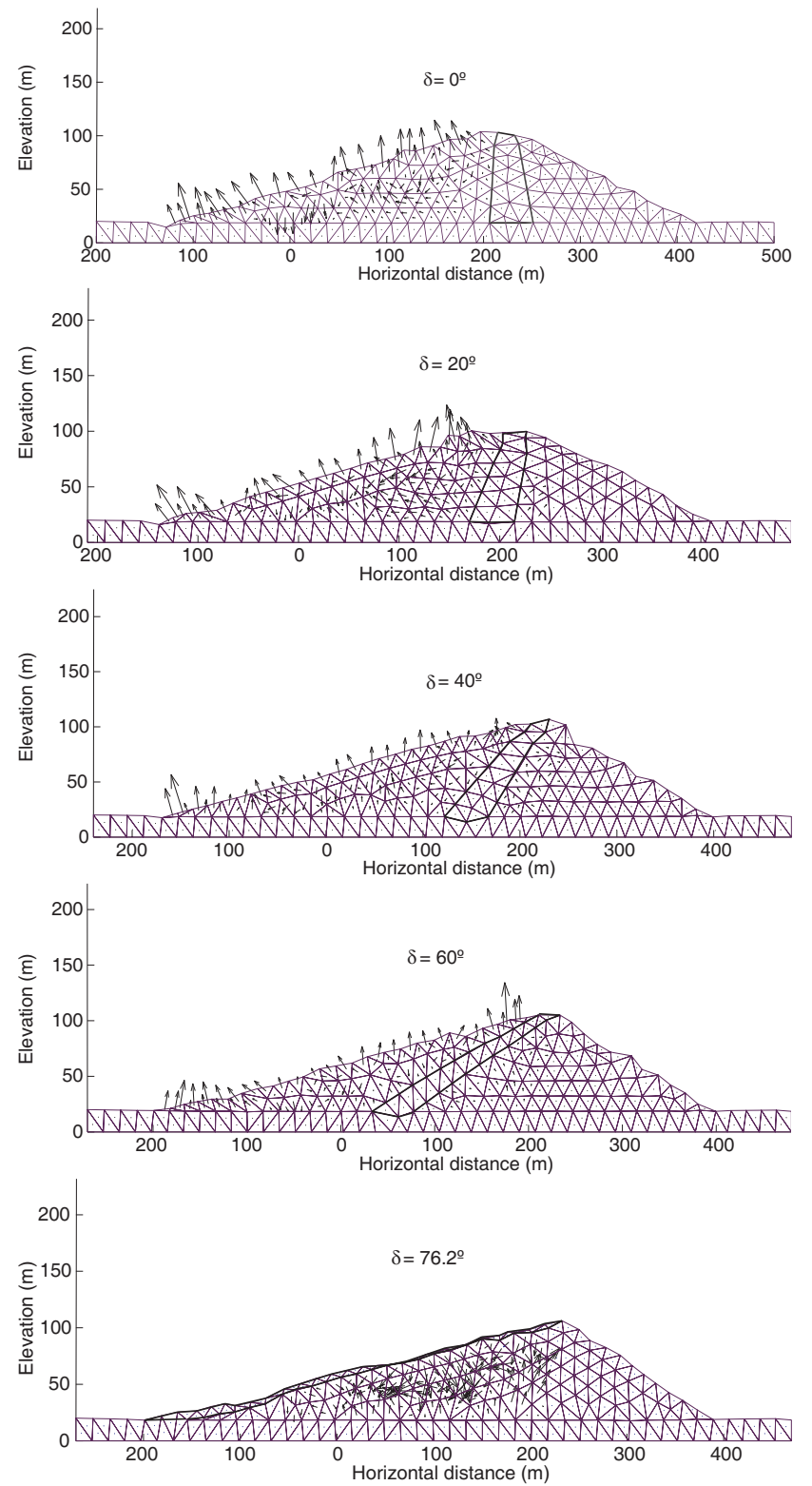

Fig. 7. Deformed shapes (amplification factor $=50$ ) of the analysed dams at time $t=8.52 \mathrm{~s}$ of the San Fernando earthquake (subjected only to its horizontal component). The vectors show the directions of the water flow inside the dams.

between all the analysed cases, the next criteria are to be taken into consideration:

- Maximum liquefaction degree reached in the dam during the earthquake: the greater it, the greater the risk of failure.

- Volume of the liquefied soil in the dam: as the percentage of liquefied volume in the dam increases, the collapse of the whole structure is more likely to occur. 


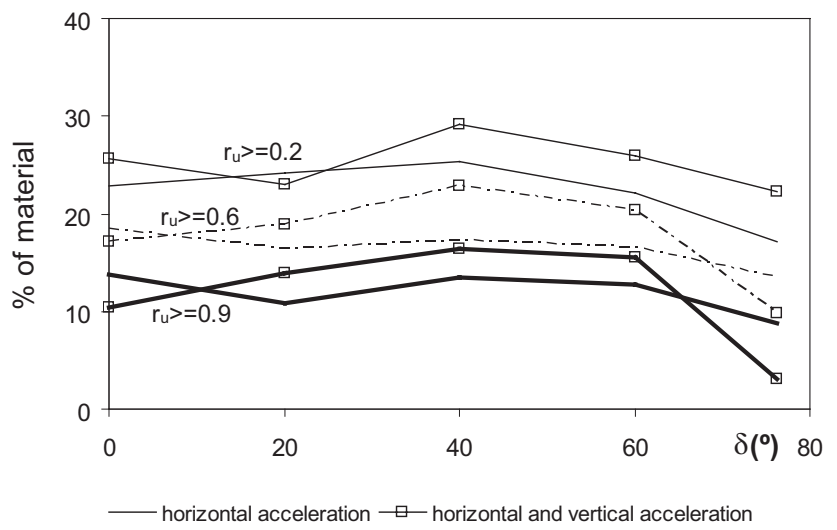

Fig. 8. Percentage of dam material over the depicted liquefaction degrees, $r_{u}$, against the angle of the impervious core, $\delta$, at the end of the San Fernando earthquake. Results for only horizontal and both horizontal and vertical accelerations are provided.

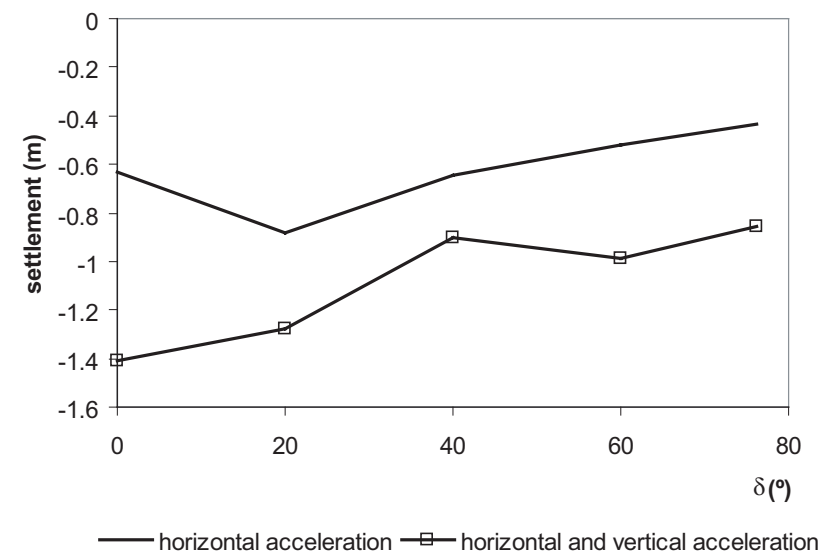

Fig. 9. Settlement of the crest dam at the end of the San Fernando earthquake, against the angle of the impervious core, $\delta$. Results for only horizontal and both horizontal and vertical accelerations are provided.

- Crest settlement: the greater it, the more likely the flow of water over the dam, which may imply the whole dam collapse.

From the numerical results introduced in Sect. 4, at the end of the first considered horizontal input motion (San Fernando earthquake), liquefaction is reached in all the analysed dams, and this is the reason why, in this case, the maximum liquefaction degree is not a criterium to determine the optimal cross section.

It is noticeable that the cross section with the minimum percentage of soil over $r_{u}=0.9$ (Fig. 8) (for both cases of only horizontal and both horizontal and vertical input motions in the same earthquake) is the one corresponding to the most inclined core, (i.e. the core at the upstream slope), which is $8.77 \%$ and $3.08 \%$, respectively. By analyzing the other two

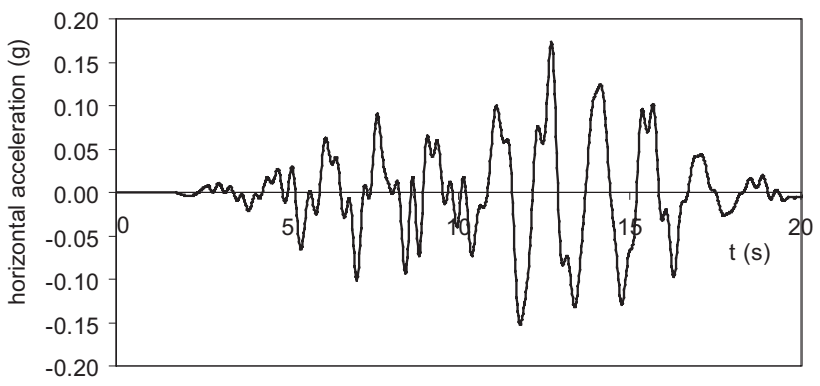

Fig. 10. Horizonal accelerogram reported by Byrne (2005), which has a $2 \%$ probability of being exceeded in $50 \mathrm{y}$ in the Vancouver area.

sets of graphs in this figure, corresponding to the other values of $r_{u}$, it is worth to point out that the minimum values of the percentages are always reached for the highest $\delta$, which means that, for this angle of the core, the degradation state of the soil is minimum.

The biggest settlement for the case of the application of only horizontal acceleration (Fig. 9) is calculated for $\delta=20$ degree, and it amounts $88 \mathrm{~cm}$. For the case of application of both input motions together, the biggest settlement occurs for the core at the centre of the dam $(140 \mathrm{~cm})$. However, in both cases, the best cross section is again the one with the maximum $\delta$, for which the numerical computation yields a value of $43 \mathrm{~cm}$ and $86 \mathrm{~cm}$, respectively. Therefore, from the numerical calculations of this deterministic analysis, the optimal cross section of earthfill dams against liquefaction at a seismic site, with the soils involved in this particular case and the applied dynamic loading, seems to be the one in which the impervious core is totally leaned to the upstream slope.

By analysing the results derived from the second computation (using the Vancouver horizontal input motion - Fig. 10), the comparative results yield the same optimal cross section: although liquefaction is reached in all the analysed geometries, the less degradated dam is again the one with the core at the upper slope (Fig. 11: percentage of dam with $r_{u} \geq 0.9$ equal to 6.28). From the inspection of Fig. 12, the smallest settlement is not obtained for the same cross section but for the one with $\delta=60$ degree $(74 \mathrm{~cm})$. However, for the most inclined core the settlement is almost the same $(86 \mathrm{~cm})$.

From the criterium of the behaviour of dams against liquefaction, the optimal cross section obtained herein is equivalent to earth dams with upstream impervious membranes, like concrete or asphalt. These membranes work as barriers preventing the flow of liquefied material through the dam towards the reservoir. However, in order to avoid the dam collapse in an earthquake, the resistance of the membrane itself against seismic loading is to be assessed, to avoid as much as possible the development of cracks and leaks which the liquefied soil may pass through. On this sense, the use of asphalt may be more adequate than concrete, which is a more rigid material. 


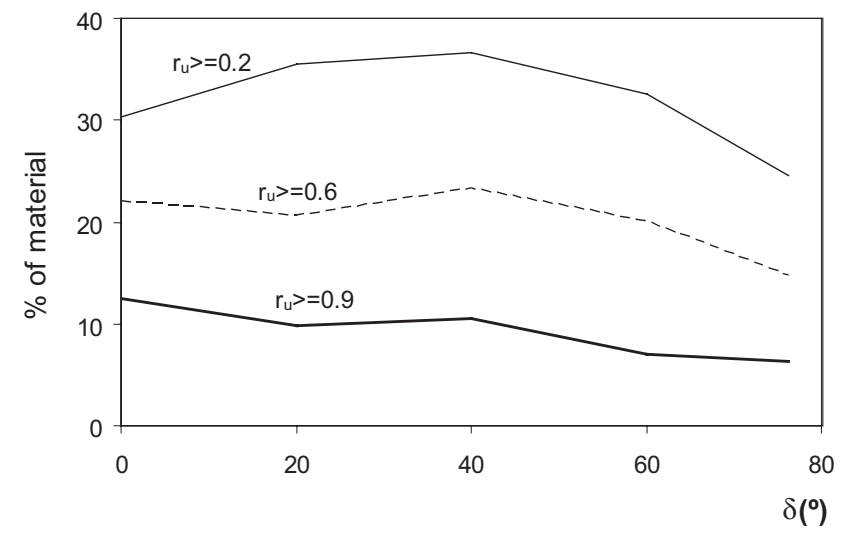

Fig. 11. Percentage of dam material over the depicted liquefaction degrees, $r_{u}$, against the angle of the impervious core, $\delta$, at the end of the Vancouver horizontal accelerogram.

\section{Conclusions}

In this paper the application of a recently developed coupled numerical model to the dynamic analysis of earth dams under earthquakes has been described, in order to explore the influence of the impervious core location inside the dams on their failure risk due to liquefaction. After a brief description of the model, the geometry of the five analysed dams has been defined. All dams are $100 \mathrm{~m}$ height, and the core location ranges from totally centered to totally leaned to the upstream slope. The five analysed dams are strictly stable under static loadings, and all of them are subjected to a couple of earthquakes at the rigid base. The main findings show that:

- Liquefaction is reached in all these dams under the selected accelerograms.

- The optimal cross section against soil degradation (in terms of liquefaction degree) is the one with the core located at the upstream slope for both earthquakes.

- The dam which suffers the minor crest settlement is again the one with the most inclined core in one of the cases, and in the second one, this settlement is on the range of the minimum computed value.

In addition, it has been justified that, in this optimal cross section, consolidation does not take place during the earthquake, but after it, and the excess pore water pressure is slowly dissipated through the downstream earthfill, which ensures the safety of this type of dams.

Therefore, the location of the impervious core at the upstream slope may be a design criteria in seismic sites, although in every particular situation, an analysis similar to the one developed in this paper should be done, following the same guidelines pointed out by considering the exact dam

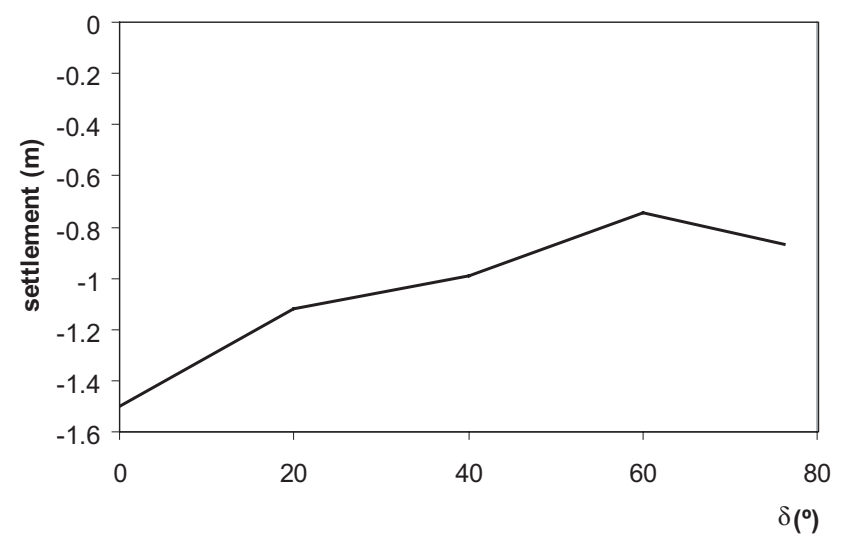

Fig. 12. Settlement of the crest dam at the end of the Vancouver horizontal accelerogram, against the angle of the impervious core, $\delta$.

height, material properties and seismic loadings. In addition, the breakage of the core must be prevented, because the maximum generated pressures during the earthquake appear at the boundary between impervious and granular materials. The optimal location of the core being at the upstream slope, its slenderness should be prevented in order to ensure the safety of the dam, because the failure of the core may cause a located flow of liquefied soil, with the result of the whole dam collapse. Another kind of dams, i.e. earth dams with impervious membranes, could be better from this point of view.

Acknowledgements. This study has been partially supported by the postdoctoral grant EX-2006-1097, given to the first author by the Spanish Ministry of Science and Education. This financial support is gratefully appreciated by the authors.

Edited by: S. Tinti

Reviewed by: 3 anonymous referees

\section{References}

Alarcón-Guzmán, A., Leonards, G. A., and Chameau, J. L.: Undrained monotonic and cyclic strength of sands, J. Geotech. Eng., 114, 1089-1109, 1988.

Bardet, J. P.: Scaled memory model for cyclic behavior of soils, J. Geotech. Eng., 121, 766-775, 1995.

Bardet, J. P. and Davis, C. A.: Performance of San Fernando Dams during 1994 Northridge earthquake, J. Geotech. Eng., 122, 554564, 1996.

Biot, M. A.: Theory of propagation of elastic waves in fluidsaturated porous solid. I, J. Acoust. Soc. Am., 28, 168-178, 1956.

Blázquez, R. and López-Querol, S.: Generalized densification law for dry sand due to dynamic loading, Soil Dyn. Earthq. Eng., 26, 888-898, 2006. 
Blázquez, R. and López-Querol, S.: Endochronic-based approach to the failure of the Lower San Fernando Dam in 1971, J. Geotech. Geoenviron., 133, 1144-1153, 2007.

Blázquez, R., Krizek, R. J., and Bažant, Z. P.: Site factors controlling liquefaction, J. Geotech. Eng.-Asce, 106, 785-801, 1980.

Byrne, P. M.: Earthquake induced damage mitigation from soil liquefaction, available at:http://www.civil.ubc.ca/liquefaction/, 2005.

Dafalias, Y. F. and Popov, E. P.: Plastic internal variable formalism of cyclic plasticity, J. Appl. Mech., 98, 645-650, 1976.

Davis, C. A. and Bardet, J. P.: Performance of two reservoirs during 1994 Northridge earthquake, J. Geotech. Eng., 122, 613-622, 1996.

Finn, W. D. L. and Khanna, J.: Dynamic response of earth dams, in: Third Symposium on Earthquake Engineering, Sah Cement Company, New Delhi (India), 1966.

Gajo, A. and Wood, D. M.: A kinematic hardening constitutive model for sands: the multiaxial formulation, Int. J. Numer. Anal. Met., 23, 925-965, 1999.

Ishihara, K., Tatsuoka, F., and Yasuda, S.: Undrained deformation and liquefaction of sand under cyclic stresses, Soils Found., 15, 29-44, 1975.

López Querol, S.: Modelización geomecánica de los procesos de densificación, licuefacción y movilidad cíclica de suelos granulares sometidos a solicitaciones dinámicas , E. T. S. Ingenieros de Caminos, Canales y Puertos, Universidad de Castilla-La Mancha, Ciudad Real (Spain), Ph.D. thesis, 2005 in Spanish.

López-Querol, S. and Blázquez, R.: Liquefaction and cyclic mobility model for saturated granular media, Int. J. Numer. Anal. Met., 30, 413-439, 2006.

López-Querol, S. and Blázquez, R.: Validation of a new endochronic liquefaction model for granular soil by using centrifuge test data, Soil Dyn. Earthq. Eng., 27, 920-937, 2007.

Manzari, M. T. and Dafalias, Y. F.: A critical state two-surface plasticity model for sands, Geotechnique, 47, 255-272, 1997.

Martin, G. R., Finn, W. D. L., and Seed, H. B.: Fundamentals of Liquefaction under Cyclic Loading, J. Geotech. Eng., 101, 423438, 1975

Mejia, L. H., Sun, J. I., and Leung, K. K.: Seismic upgrade of hydraulic fill dam buttressing, Soil Dyn. Earthq. Eng., 25, 571-579, 2005.

Ming, H. Y. and Li, X. S.: Fully coupled analysis of failure and remediation of Lower San Fernando Dam, J. Geotech. Geoenviron., 129, 336-349, 2003.

Mira, P., Pastor, M., Li, T., and Liu, X.: A new stabilized enhanced strain element with equal order of interpolation for soil consolidation problems, Comput. Method. Appl. M., 192, 4257-4277, 2003

Olson, S.: Liquefaction analysis of level and sloping ground using field case histories and penetration resistance, $\mathrm{Ph} . \mathrm{D}$. thesis, University of Illinois at Urbana-Champaign, Urbana, Illinois, (available at:http://pgi-tp.ce.uiuc.edu/olsonwebfiles/olsonweb/index. htm), 2001
Olson, S. M. and Stark, T. D.: Liquefied strength ratio from liquefaction flow case histories, Can. Geotech. J., 39, 329-347, 2002.

Papadimitriou, A. G., Bouckovalas, G. D., and Dafalias, Y. F.: Plasticity model for sand under small and large cyclic strains, J. Geotech. Geoenviron., 127, 973-983, 2001.

Pastor, M., Zienkiewicz, O., and Chan, A.: Generalized plasticity and the modelling of soil behaviour, Int. J. Numer. Anal. Met., 14, 151-190, 1990.

Prevost, J. H.: A simple plasticity theory for frictional cohesionless soils, Soil Dyn. Earthq. Eng., 4, 9-17, 1985.

Seed, H. B.: 19TH Rankine Lecture - Considerations in the earthquake resistant design of earth and rock fill dams, Géotechnique, 98, 213-263, 1979.

Seed, H. B., Lee, K. L., Idriss, I. M., and Makdisi, F. I.: Analysis of the slides in the San Fernando Dams during the earthquake on 9 February 1971, Tech. Rep. EERC 73-2, Earthquake Engineering Research Center, University of California, Berkeley, CA, 1973.

Seed, H. B., Seed, R. B., Harder, L. F., and Jong, H. L.: Reevaluation for the lower San Fernando dam, Report 2, Examination of the post-earthquake slide of 9 February 1971, H. Bolton Seed, Inc., Department of the Army, US Army Corps of Engineers, 1989.

Sherard, J. L.: Earthquake considerations in earth dam design, J. Soil Mech. Found. Div. - ASCE, 93, 377-401, 1967.

Vallarino, E.: Tratado básico de presas, Colegio de Ingenieros de Caminos, Canales y Puertos, Colección Seinor, 2001 in Spanish.

Wieland, M. and Malla, S.: Seismic safety evaluation of a $117 \mathrm{~m}$ high embankment dam resting on a thick soil layer, Paper 128, in: 12th European Conference on Earthquake Engineering, edited by Ltd., E. S., 2002.

Wijewickreme, D., Sriskandakumar, S., and Byrne, P.: Cyclic loading response of loose air-pluviated Fraser River sand for validation of numerical models simulating centrifuge tests, Can. Geotech. J., 42, 550-561, 2005.

$\mathrm{Wu}, \mathrm{G}$.: Earthquake-induced deformation analyses of the Upper San Fernando Dam under the 1971 San Fernando Earthquake, Can. Geotech. J., 38, 1-15, 2001.

Wylie, E. B., Streeter, V. L., Papadakis, C. N., and Richart Jr., F. E. Earthquake resistance of earth and rock-fill dams. Repor 4: Transient two-dimensional analysis of soils by Latticework method, Lopez dam case study, Tech. rep., Department of Civil Engineering. The University of Michigan, Ann Arbor, Mich., 48104, 1975.

Zienkiewicz, O. C. and Xie, Y. M.: Analysis of Lower San Fernando dam failure under earthquake, Dam Engineering, 2, 307322,1991

Zienkiewicz, O. C., Chang, C. T., and Bettes, P.: Drained, undrained, consolidating and dynamic behaviour assumptions in soils, Géotechnique, 30, 385-395, 1980.

Zienkiewicz, O. C., Chan, A. H. C., Pastor, M., Scherefler, B. A., and Shiomi, T.: Computational Geomechanics with Special Reference to Earthquake Engineering, John Wiley \& Sons Ltd, Chichester, England, 1999. 